\title{
Efficient and sustainable water systems management toward worth living development
}

\author{
Vasilis Kanakoudis $^{1}$ • George Karatzas ${ }^{2}$
}

Received: 9 August 2017 / Accepted: 11 August 2017 /Published online: 19 August 2017

(C) Springer-Verlag GmbH Germany 2017

It is well known that global water-related problems are mainly due to water scarcity and climate change. Water demand is increasing rapidly and water systems are stressed by many human factors. "Sustainable Development" stating that "... the opportunity cost (cost of equal chances) between generations should remain intact..." guarantees that things will not get worse as time passes by. However, it does not safeguard that given the current conditions, things will get better. Based on the historical path of humanity, it is more than certain that next generations will probably be forced to face worst conditions related to the satisfaction of their basic needs, compared to their ancestors. The new prevailing concept of "Worth Living Development," tending to replace Sustainable Development, states that “...the opportunity cost between generations should be gradually decreased to take under consideration the additional threats future generations will probably have to face...". Thus, each generation will hand over to the next one a better place to live in.

This special issue of Environmental Science and Pollution Research presents a collection of five papers initially presented at the 2nd EWaS International Conference "Efficient \& Sustainable Water Systems toward Worth Living Development". The conference was held on June 1-4, 2016, in

Responsible editor: Philippe Garrigues

Vasilis Kanakoudis

bkanakoud@civ.uth.gr

George Karatzas

karatzas@mred.tuc.gr

1 Civil Engineering Department, University of Thessaly, Volos, Greece

2 School of Environmental Engineering, Technical University of Crete, Chania, Crete, Greece
Platanias/Chania, Crete, Greece (http://www.ewas2.tuc.gr/). The conference was co-organized by the University of Thessaly/Civil Engineering Department and the Technical University of Crete/ School of Environmental Engineering, (co-chairmen: V. Kanakoudis-University of Thessaly, G. Karatzas-Technical University of Crete, vice chairman: E. Keramaris-University of Thessaly). EWaS series of conferences started in 2013, when the first EWaS conference was held in Thessaloniki.

The conference highlighted the need to improve the efficiency and sustainability of all water systems in a changing and fragile environment, especially under the frustrating economic conditions we are facing today. The current special issue of Environmental Science and Pollution Research was guest-edited by Associate Professor Vasilis Kanakoudis (University of Thessaly, Volos, Greece). The papers included in this special issue are based on the ones initially presented at the conference. However, they have been extended (by at least $50 \%$ ) and revised having gone through the regular peer-review process of the Environmental Science and Pollution Research journal. The topics the papers included in the current issue dealt with are briefly being presented as follows:

1. Bastidas et al. (2017) developed methodologies based on optimization techniques using geographic information system (GIS) technology and a matter-element analysis of 5-day biological oxygen demand $\left(\mathrm{BOD}_{5}\right)$ and total suspended solids (TSS) for the design and redesign of water quality monitoring networks. The methodologies were applied in Andean basins resulting in a flexible, objectively based design for a watershed without prior water quality data and a network redesign of a watershed with historical water quality monitoring. Network redesign identified network redundancy, which resulted in a $64 \%$ reduction in the number of water quality monitoring stations 
along the channel, and a $78 \%$ reduction of stations throughout the basin.

2. Dimkić et al. (2017) discuss a climate change adaptation measure - the possibility of karst spring overexploitation, where there is a siphon-shaped cavity inside the mountain. The case presented in the paper is the Krupac water supply source in Serbia, providing additional water in the dry season in the city of Niš. The paper presents a non-standard project which secured additional amounts of drinking water in a highly cost-effective way. Such projects might be applicable to some other regions in karst, especially if there is a siphon-shaped cavity inside the mountain.

3. Kanakoudis et al. (2017) analyzed the vulnerability of water resources in the Adriatic Sea region focusing on Corfu Island, Greece. The study presents the results of the application of a common methodological framework for water resources management applied in Adriatic Sea during the DRINKADRIA project. Climate characteristics and climate change, water resources quality, water resources and drinking water supply availability, and water resources safety were assessed for the study area. The results showed that climate change is expected to impact negatively on water resources availability while at the same time water demand is expected to increase. Water quality problems will be intensified especially due to land use changes and salt water intrusion. The analysis identified areas where water resources are more vulnerable, allowing decision makers develop management strategies.

4. Machado et al. (2017) assessed the human health risks of environmental exposure to metals and herbicides through water and fish intake. Various metals were analyzed in river water and edible fish and herbicides were analyzed in river water, taking into consideration seasonal variance in Pardo river. The study results revealed that there are important anthropogenic pressures having negative impacts on river water quality. Agriculture was also identified as a major contributor to water pollution. Considering the importance of the Pardo river as a water source for public supply in some municipalities, and the persistence of metals and herbicides in the environment, the results indicated that there was a seasonal influence on the non-carcinogenic and carcinogenic risk to human health, especially in the rainy season. The authors suggested that studies for water treatment plants implantation should consider the risks of exposure to persistent substances, to protect the population.

5. Savvidis et al. (2017) investigated numerically and experimentally the optimum design of the entrance of a fishpond laterally to the main flow of an open channel. The comparison of the final results of the mathematical models with the findings of the physical model revealed the hydrodynamic interaction and coupling between the main flow of the channel and the lateral reservoir, leading to the optimum technical design of the system.

\section{References}

Bastidas JC, Vélez JJ, Zambrano J, Londoño A (2017) Design of water quality monitoring networks with two information scenarios in tropical Andean basins. Environ Sci Pollut Res. doi:10.1007/s11356017-9021-6

Dimkić D, Dimkić M, Soro A, Pavlović D, Jevtić G, Lukić V, Svrkota D (2017) Overexploitation of karst spring as a measure against water scarcity. Environ Sci Pollut Res. doi:10.1007/s11356-017-9001-x

Kanakoudis V, Tsitsifli S, Papadopoulou A, Cencur Curk B, Karleusa B (2017) Water resources vulnerability assessment in Adriatic Sea region: the case of Corfu Island. Environ Sci Pollut Res. doi:10. 1007/s11356-017-9732-8

Machado CS, Fregonesi BM, Alves RI, Tonani KA, Sierra J, Martinis BS, Celere BS, Mari M, Schuhmacher M, Nadal M, Domingo JL, Muñoz SS (2017) Health risks of environmental exposure to metals and herbicides in the Pardo River, Brazil. Environ Sci Pollut Res. doi:10.1007/s11356-017-9461-Z

Savvidis Y, Keramaris E, Pechlivanidis G, Koutitas C (2017) Optimum design of the entrance of a fishpond laterally to the main stream of an open channel. Environ Sci Pollut Res. doi:10.1007/s11356-017-8696-Z

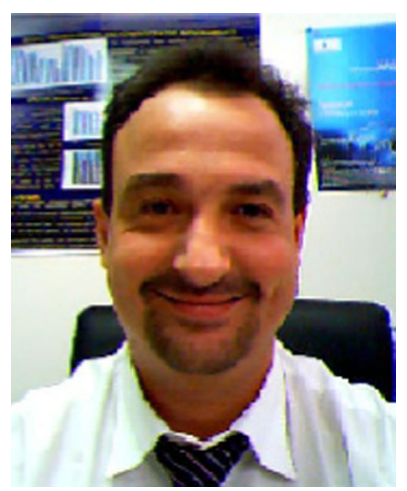

Dr. Vasilis Kanakoudis is the Associate Professor in Water Resources \& Drinking Water Networks Management, and also the Head of the Civil Engineering Department at the University of Thessaly, Greece. He is working in the field of Drinking Water Networks and Water Resources Management since 1993. His scientific expertise includes water supply systems hydraulic simulation and optimization, water balance assessment, performance indicators assessment, water resources vulnerability assessment, water age and water quality modeling in water pipe networks, energy recovery through PATs, water pricing, etc. He has published 55 journal papers, 12 papers in special editions, 108 papers in conference proceedings, 1 book, and 1 book chapter in the abovementioned topics and he has coordinated 16 relevant projects over the last 9 years. He is a reviewer for 24 scientific journals (ASCE, Elsevier, IWAp, MDPI, Springer, Taylor \& Francis), having reviewed 230 papers over the last 9 years. He has received the ASCE OUTSTANDING REVIEWER award. He is a representative of the Special Secretariat for Water (Greek Ministry of Environment and Energy) regarding the implementation monitoring of the WFD 2000/60/EC and a member of the 5member special multidisciplinary committee of the Special Secretariat for Water (SSW). SSW is the competent authority for the implementation of the WFD in Greece. Last but not least, Dr. V. Kanakoudis is fully dedicated in his motto: "still doing pipes"... 


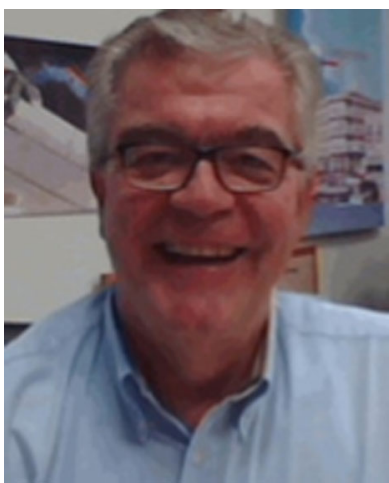

Prof. George P. Karatzas received his Ph.D in 1992 from the Department of Civil Engineering of Rutgers University, USA, in a combined Ph.D with Princeton University, USA. At the present time, he is the Dean and a Full Professor in the School of Environmental Engineering at the Technical University of Crete, Greece (1999-today). Prior to that position, he worked as a postgraduate at the Research Center for Groundwater Remediation Design at the University of Vermont (1992-1994) and as an assistant professor at the Civil Engineering Department of the University of Vermont (1994-1999). His area of research includes numerical simulation in porous media, subsurface hydrology and contaminant transport, groundwater management, subsurface remediation techniques, global optimization techniques, surface water modeling, and floods. He is the author of 72 journal publications, 84 conference proceedings, 1 book, and 5 book chapters. He is an associate editor of the Journal of Hydroinformatics. 